\title{
Comparison of Tracheal Diameter Measurements on Radiograph Versus Computed Tomography at a Tertiary Care Hospital in Pune, Central India
}

Pranav Ajmera ${ }^{1}$, Niharika Prasad ${ }^{1}$

1. Radiology, Dr DY Patil Medical College, Hospital and Research Center, Pune, IND

Corresponding author: Pranav Ajmera, pranavajmera@gmail.com

\section{Abstract}

\section{Background}

Variations in tracheal diameter with respect to factors like age and gender are one of the major factors affecting the size of the endotracheal tube (ETT) preferred in a patient. It is important to pre-determine this figure because a tube of a larger size predisposes the patient for tracheal mucosal ischemia, while one of a smaller size may not ensure adequate oxygen saturation in the patient.

\section{Purpose}

We undertook this study to assess the accuracy of radiograph versus computed tomography (CT) and comment on whether a CT should be carried out mandatorily in all patients where intubation is needed.

\section{Materials and methods}

The study was undertaken at Dr DY Patil Medical College, Hospital, and Research Center, a tertiary care institute in Pune, India. A total of 217 patients in whom both chest radiograph and chest CT were performed were enrolled in the study and measurements were performed at suitable landmarks which correspond to the position of endotracheal tubes.

\section{Results}

The males had a mean age of 44.2 years and females of 41.7 years. The mean X-ray transverse diameter was $15.4 \pm 3.2$ (SD) $\mathrm{mm}$, mean CT axial transverse diameter was $15.3 \pm 3.4$ (SD) $\mathrm{mm}$, mean CT sagittal diameter was $14.8 \pm 3.7(\mathrm{SD}) \mathrm{mm}$, and the mean CT coronal diameter was $15.2 \pm 3.5(\mathrm{SD}) \mathrm{mm}$.

\section{Conclusions}

There was a significant difference in mean X-ray transverse diameter (Low kV), CT axial transverse diameter, CT sagittal diameter, and CT coronal diameter between males and females. Mean values were significantly higher in males as compared to females. There was a significant difference in tracheal diameters for different age groups, irrespective of the modality. Bland-Altman analysis revealed no significant difference between chest radiograph and CT for tracheal diameter measurement.

\section{Introduction}

Variations in tracheal diameter with respect to factors like age and gender are one of the major factors affecting the size of the endotracheal tube (ETT) preferred in a patient. It is important to pre-determine this figure because a tube of a larger size predisposes the patient for tracheal mucosal ischemia, while one of a smaller size may not ensure adequate oxygen saturation in the patient [1,2]. Plain computed tomography (CT) is a highly accurate modality to estimate the overall diameter of the trachea (DT) at that particular instant, whether it is the anteroposterior (AP) or transverse diameter, and whether the diameter is measured in inspiratory or expiratory position. But a CT is costly in comparison to a radiograph. The delineation of different tissues on an X-ray varies with the kilovolts peak and is affected by factors like obesity and is liable to scattering, all of which affect the final quality of radiograph obtained, and hence, the measurements $[3,4]$. Hence, we undertook this study to assess the accuracy of radiograph versus CT in all those cases in which both were performed. An analysis of the accuracy would be useful in determining whether a CT should be carried out mandatorily in all patients where intubation is needed and CT is possible, in order to ensure fewer complications post-intubation.

\section{Materials And Methods}


This was a prospective study performed at Dr DY Patil Medical College, Hospital, and Research Center, a tertiary care institute in Pune, India, over a 12-month period between May 2019 to May 2020. As a part of the study, only those patients were enrolled who had undergone both chest radiography and chest CT before being intubated. However, amongst this group, only those patients were analysed who were not suffering from any prior airway diseases, such as chronic obstructive pulmonary disease or having an acute exacerbation of any airway disease, as the inflammation process narrows the inner tracheal diameter. Also excluded were patients who had undergone any thoracic procedure or chest surgery in the previous three months, patients already having an indwelling ETT or airway in-situ, and patients with a suboptimal radiograph that is either over- or underexposed.

The CT was performed on a 128-slice Philips Ingenuity CT scanner (Philips Medical Systems Nederland B.V., Eindhoven, The Netherlands), while the radiographs were acquired on a $500 \mathrm{~mA}$ (milliampere) machine with settings maintained at $55 \mathrm{kV}$ (kilovolts), except in cases where the patient was obese, where it was kept at 60 $\mathrm{kV}$.

Comparisons were made using standard anatomical landmarks, which have been used in previous studies, like the one performed by Sakuraba et al. [2]. For CT, this implied measuring the transverse diameter at the level of the body of the seventh cervical vertebra. In the current study, measurements were also drawn for the coronal and sagittal diameter; these measurements were made after three-dimensional reconstruction of the image at the same level. This was ensured by utilising the triangulating tool to identify the exact point on the axial image in coronal and sagittal sections. On the radiograph images, the transverse diameter was measured by drawing a hypothetical line at the level of bilateral sternal ends of the clavicle. These specific landmarks correspond to the location where the inflated cuff of ETT contacts the mucosa.

\section{Statistical analysis}

Data was analyzed using SPSS version 22 software (IBM Corp., Armonk, NY, USA). Categorical data was represented in the form of frequencies and proportions. Continuous data was represented as mean and standard deviation.

The independent t-test was used as a test of significance to identify the mean difference between two quantitative variables. ANOVA (analysis of variance) was the test of significance to identify the mean difference between more than two groups for quantitative data. Pearson correlation was done to find the correlation between two quantitative variables [5-7].

Bland-Altman plot was used to describe the agreement between the two quantitative measurements. Pvalue (the probability that the result is true) of $<0.05$ was considered as statistically significant.

\section{Results}

The study included 217 patients, among whom 120 were males and 97 were females The males had a mean age distribution of 44.2 years, and the females had a mean of 41.7 years. A comparison of the mean transverse diameter on radiograph and mean diameter on CT axial view between the two genders revealed a mean figure of $16.3 \mathrm{~mm}(\mathrm{SD}=3.6 \mathrm{~mm}$ ) in males and $14.3 \mathrm{~mm}(\mathrm{SD}=2.2 \mathrm{~mm}$ ) in females for the radiograph. In the case of CT, the mean figure for axial diameter was $16.7 \mathrm{~mm}(\mathrm{SD}=3.4 \mathrm{~mm})$ in males and $13.6 \mathrm{~mm}(\mathrm{SD}=$ $2.5 \mathrm{~mm}$ ) in females; for sagittal diameter, it was $16.3 \mathrm{~mm}(\mathrm{SD}=3.7 \mathrm{~mm})$ in males, $13 \mathrm{~mm}(\mathrm{SD}=2.7 \mathrm{~mm})$ in females; for coronal diameter, it was $16.5 \mathrm{~mm}(\mathrm{SD}=3.3 \mathrm{~mm}$ ) in males, $13.5 \mathrm{~mm}(\mathrm{SD}=2.8 \mathrm{~mm})$ in females.

In the study, among males, there was a significant difference in mean X-ray transverse diameter (low $\mathbf{k V}$ ), CT axial transverse diameter, CT sagittal diameter, and CT coronal diameter with respect to age distribution. Mean X-ray transverse diameter was highest among subjects in the age group 50 to 59 years; mean CT axial transverse diameter was highest among subjects in the age group 70 to 79 years; mean CT sagittal diameter was highest among subjects in the age group 70 to 79 years and 50 to 59 years; and mean CT coronal diameter was highest among subjects in the age group 70 to 79 years (Table 1 ). 


\section{Cureus}

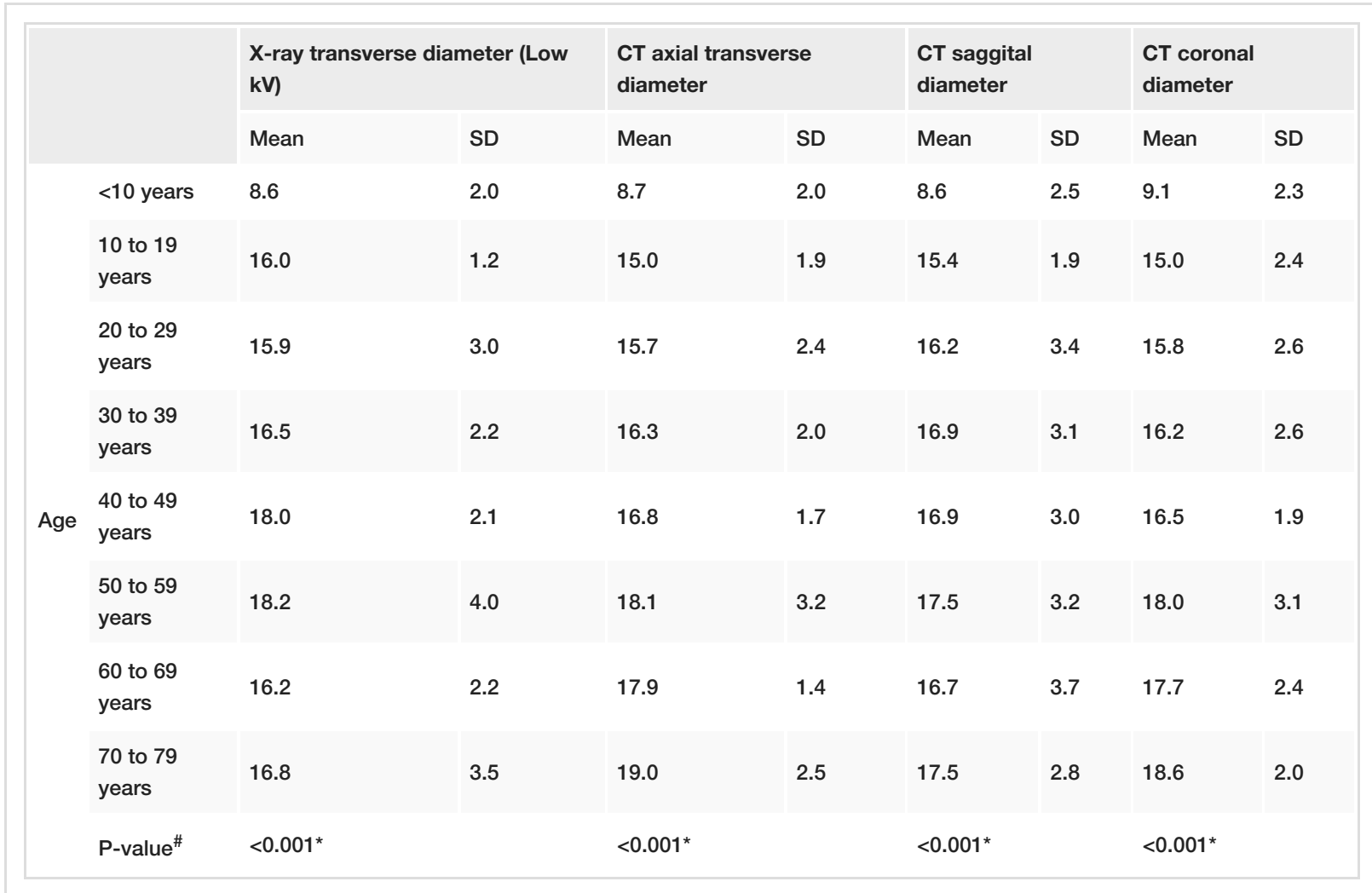

TABLE 1: Mean transverse, coronal, and sagittal tracheal diameters in normal subjects by age for males

\#ANOVA (analysis of variance)

In the study among females, there was a significant difference in mean X-ray transverse diameter (low $\mathrm{kV}$ ), CT axial transverse diameter, CT sagittal diameter, and CT coronal diameter with respect to age distribution. Mean X-ray transverse diameter was highest among subjects in the age group 70 to 79 years; mean CT axial transverse diameter was highest among subjects in the age group 50 to 59 years; mean CT sagittal diameter was highest among subjects in the age group 40 to 49 years; and mean CT coronal diameter was highest among subjects in the age group 40 to 49 years (Table 2). 


\section{Cureus}

\begin{tabular}{|c|c|c|c|c|c|c|c|c|c|}
\hline & & \multicolumn{2}{|c|}{$\begin{array}{l}\text { X-ray transverse diameter (low } \\
\text { kV) }\end{array}$} & \multicolumn{2}{|c|}{$\begin{array}{l}\text { CT axial transverse } \\
\text { diameter }\end{array}$} & \multicolumn{2}{|c|}{$\begin{array}{l}\text { CT sagittal } \\
\text { diameter }\end{array}$} & \multicolumn{2}{|c|}{$\begin{array}{l}\text { CT coronal } \\
\text { diameter }\end{array}$} \\
\hline & & Mean & SD & Mean & SD & Mean & SD & Mean & SD \\
\hline \multirow{9}{*}{ Age } & $<10$ years & 8.7 & 0.2 & 7.9 & 0.9 & 7.4 & 2.5 & 8.3 & 3.3 \\
\hline & $\begin{array}{l}10 \text { to } 19 \\
\text { years }\end{array}$ & 12.8 & 1.7 & 13.3 & 1.5 & 12.5 & 1.9 & 12.9 & 1.3 \\
\hline & $\begin{array}{l}20 \text { to } 29 \\
\text { years }\end{array}$ & 14.2 & 1.9 & 13.4 & 2.2 & 13.2 & 3.1 & 13.4 & 2.4 \\
\hline & $\begin{array}{l}30 \text { to } 39 \\
\text { years }\end{array}$ & 14.8 & 1.8 & 13.2 & 1.6 & 11.9 & 2.0 & 12.7 & 1.4 \\
\hline & $\begin{array}{l}40 \text { to } 49 \\
\text { years }\end{array}$ & 13.9 & 1.9 & 14.9 & 2.5 & 14.0 & 2.5 & 15.6 & 3.5 \\
\hline & $\begin{array}{l}50 \text { to } 59 \\
\text { years }\end{array}$ & 15.2 & 1.2 & 15.3 & 2.0 & 13.7 & 1.5 & 13.8 & 3.0 \\
\hline & $\begin{array}{l}60 \text { to } 69 \\
\text { years }\end{array}$ & 14.9 & 3.5 & 13.2 & 3.3 & 13.7 & 2.4 & 13.7 & 3.7 \\
\hline & $\begin{array}{l}70 \text { to } 79 \\
\text { years }\end{array}$ & 15.3 & 1.3 & 14.0 & 2.9 & 13.5 & 3.3 & 14.0 & 3.2 \\
\hline & P-value ${ }^{\#}$ & $<0.001^{*}$ & & $0.007^{\star}$ & & $0.031^{*}$ & & $0.038^{*}$ & \\
\hline
\end{tabular}

TABLE 2: Mean transverse, coronal, and sagittal tracheal diameters in normal subjects by age for females

\#ANOVA (analysis of variance)

kV: kilovolts

Overall, the mean X-ray transverse diameter was $15.4 \pm 3.2$ (SD) $\mathrm{mm}$, mean CT axial transverse diameter was $15.3 \pm 3.4$ (SD) $\mathrm{mm}$, mean CT sagittal diameter was $14.8 \pm 3.7$ (SD) $\mathrm{mm}$, and mean CT coronal diameter was $15.2 \pm 3.5(\mathrm{SD}) \mathrm{mm}$.

In the study, among both males and females, there was a significant positive correlation between X-ray transverse diameter and CT axial transverse diameter, that is, with an increase in X-ray transverse diameter, there was an increase in CT axial transverse diameter and vice versa. The Pearson correlation findings for CT axial transverse diameter in males and females were 0.588 and 0.561 , respectively. Corresponding scatter plots for males and females have been depicted in Figure 1 and Figure 2, respectively. 


\section{Cureus}

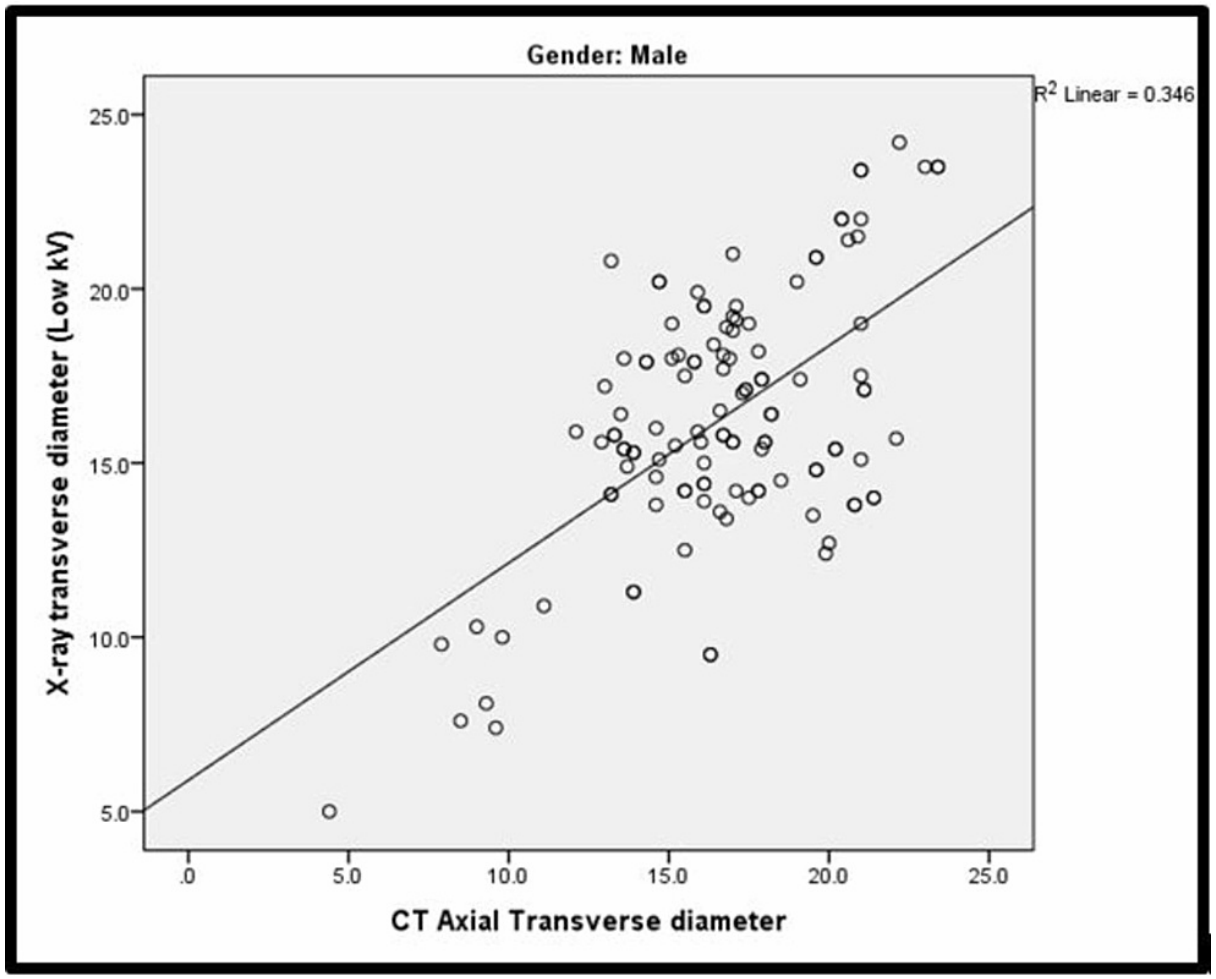

FIGURE 1: Scatter plot showing correlation between X-ray transverse diameter and CT axial transverse diameter among males kV: kilovolts

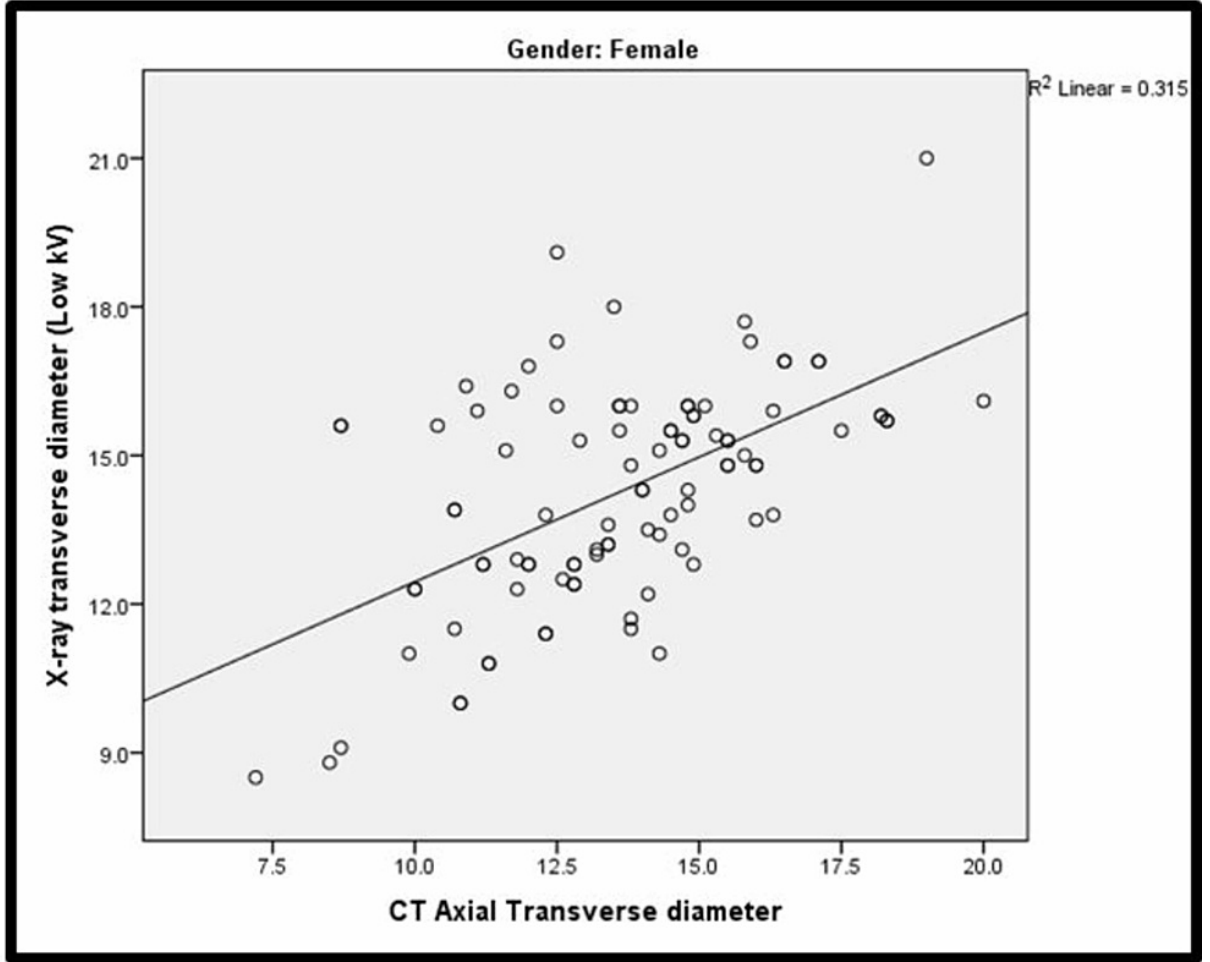

FIGURE 2: Scatter plot showing correlation between X-ray transverse diameter and CT axial transverse diameter among females kV: kilovolts 


\section{Cureus}

The Bland-Altman analysis for chest radiograph versus CT transverse diameter among males as depicted in Table 3 and Figure 3 revealed that the mean (difference between X-ray and CT transverse diameter) was $0.374 \pm 1.96$ (3.191) and the mean (difference between X-ray and CT transverse diameter) $\pm 1.96 \mathrm{SD}$ was 6.626 to 5.878 .

\begin{tabular}{|l|l|l|l|}
\hline & N & Mean & SD \\
\hline Difference between X-ray and CT transverse diameter & 120 & -0.374 & 3.191 \\
\hline Average of X-ray and CT transverse diameter & 120 & 16.469 & 3.129 \\
\hline
\end{tabular}

\section{TABLE 3: Bland-Altman analysis for X-ray vs CT transverse diameter among males}

Mean difference between X-ray and CT transverse diameter was $-0.374 \pm 1.96$ (3.191)

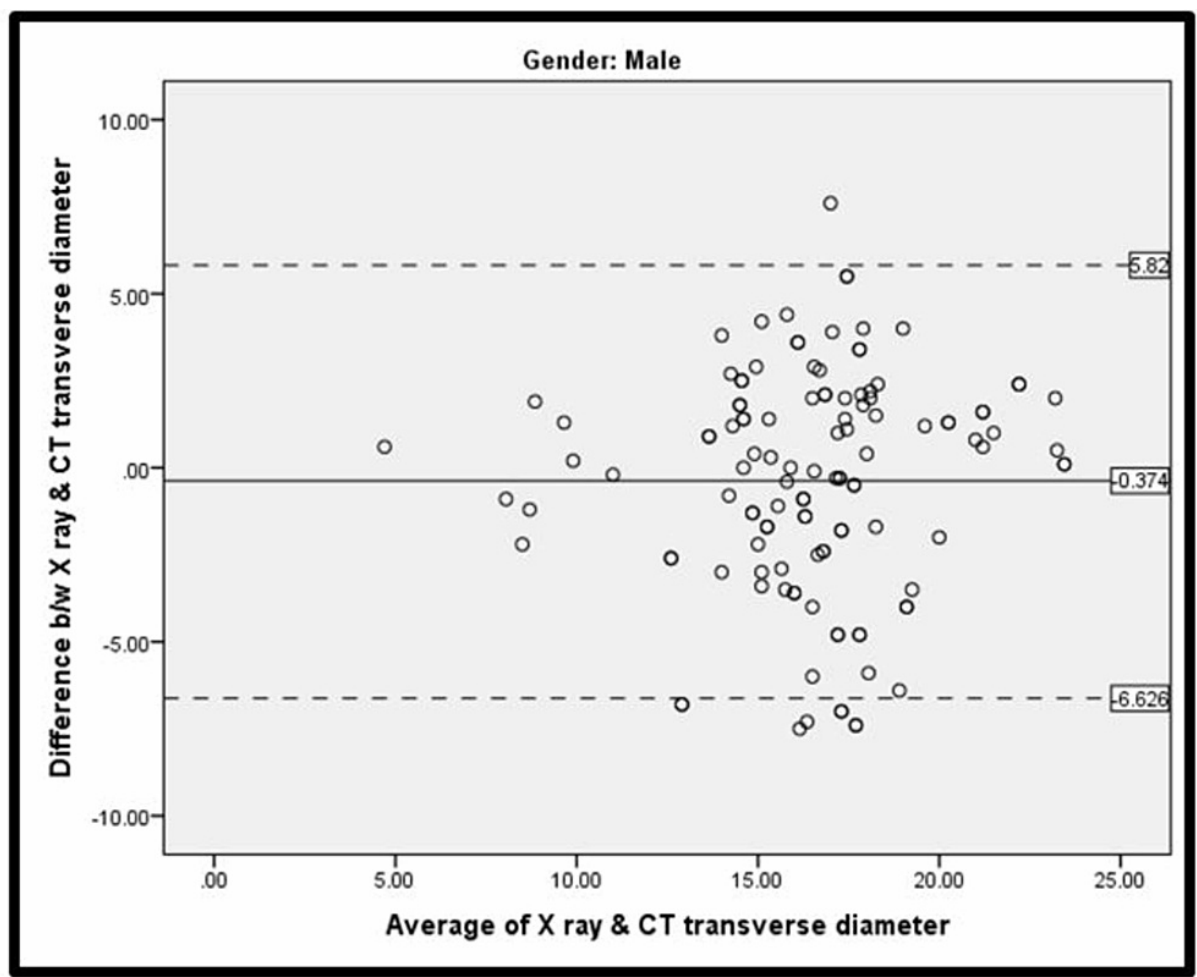

FIGURE 3: Bland-Altman plot for X-ray vs CT transverse diameter among males

The solid line shows bias, and the dotted lines show the limit of agreement.

Among females (Table 4, Figure 4), the Bland-Altman analysis revealed that the mean (difference between Xray and CT transverse diameter) was $0.654 \pm 1.96$ (2.231) and the mean (difference between X-ray and CT transverse diameter) \pm 1.96 SD was 3.658 to 4.96 . 


\section{Cureus}

\begin{tabular}{|c|c|c|c|}
\hline & $\mathbf{N}$ & Mean & SD \\
\hline Difference $b / w X$ ray \& CT transverse diameter & 97 & 0.654 & 2.231 \\
\hline Average of $X$ ray \& CT transverse diameter & 97 & 13.942 & 2.095 \\
\hline
\end{tabular}

\section{TABLE 4: Bland-Altman analysis for $\mathrm{X}$-ray vs $\mathrm{CT}$ transverse diameter among females}

Mean (difference between X-ray and CT transverse diameter) was $0.654 \pm 1.96$ (2.231)

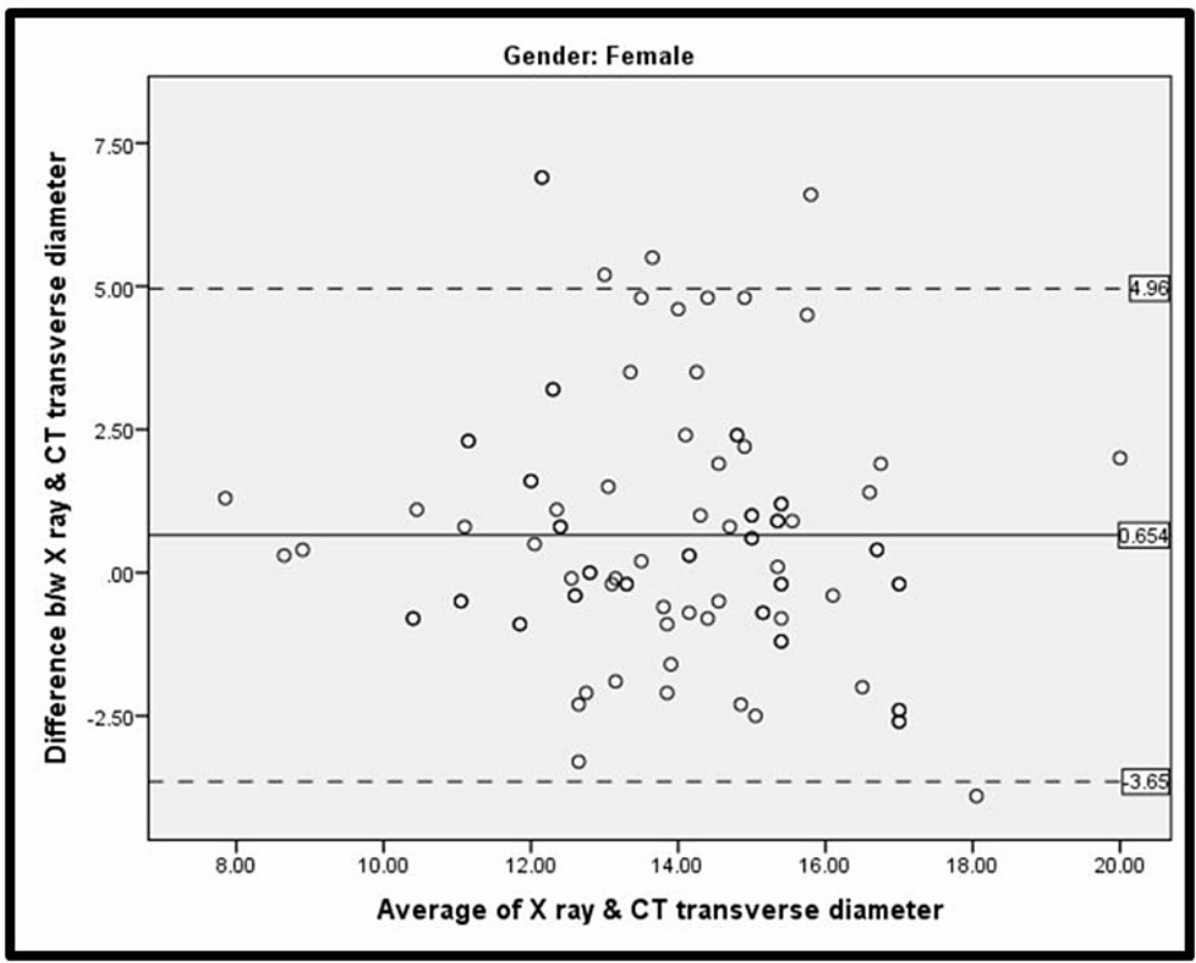

FIGURE 4: Bland-Altman plot for X-ray vs CT transverse diameter among females

The solid line shows bias, and the dotted lines show the limit of agreement.

\section{Discussion}

The knowledge of the transverse diameter of the trachea at the level where the cuff is inflated, allows the determination of the size of the endotracheal tube to be inserted and, in turn, avoid discomfort to the patient in the form of pain and hoarseness. It also avoids complications like pressure necrosis and tracheal rupture [8-11]

While data exists on the normal values for coronal and sagittal diameters, these figures are relatively old and were mostly determined utilising radiographs only. With the advent of CT, more accurate measurements can be acquired. In fact, CT happens to be the most powerful technique and gives the most superior resolution [12] in-vivo compared to other available options. Other non-invasive modalities that can be utilised to take measurements of the trachea include endotracheal-ultrasonography (EUS), magnetic resonance imaging (MRI), and bronchoscopy. CT has an advantage over the rest as EUS is operator- and technique-dependent to some extent, MRI is too costly to be practically feasible in most cases, and bronchoscopy is an invasive procedure.

In our study, we found that there was a significant difference in mean X-ray transverse diameter (low $\mathrm{kV}$ ), CT axial transverse diameter, CT sagittal diameter, and CT coronal diameter between males and females. 
Mean values were significantly higher in males as compared to females. This is similar to the results published by Mihara et al. [13] and Breatnach et al. [14] who found that both the upper and lower limit of normal in males is more than in females.

We also found that there is a significant difference in tracheal diameters for different age groups, irrespective of the modality the measurements were performed on. This is in concordance with the study performed by Mihara et al. [13]. The study though was limited in the aspect that this was a single-centre study. In future, more such studies from different parts of India should be carried out to account for differences between various regions due to environment and genetics.

\section{Conclusions}

Bland-Altman analysis revealed that the transverse diameters, whether measured on a radiograph or on a CT, were comparable to each other as most of the values were falling within the limit of agreement, except a few outliers. Hence, this implies that a radiograph, being the cheaper alternative to CT, should be preferred as there is no significant difference in tracheal dimensions measurement. The limitations of our study were that the entire patient data was collected from a single, tertiary institute, and the observations were drawn by a single radiologist with five years of experience.

\section{Additional Information \\ Disclosures}

Human subjects: Consent was obtained or waived by all participants in this study. Not applicable issued approval NA. There is no direct contact with the patient and only the PACS was searched to obtain the scanned image. At no point was actual patient identity ever revealed in this article. Mandatory consent taken before every CT thorax examination was performed is very much in place. Discussion with the ethics committee revealed that since the study is in no way in contact with human tissue, is not invasive, does not process detailed demographic patient data, and is instead a predominantly "PC based study", approval is not required and the study can proceed as such. . Animal subjects: All authors have confirmed that this study did not involve animal subjects or tissue. Conflicts of interest: In compliance with the ICMJE uniform disclosure form, all authors declare the following: Payment/services info: All authors have declared that no financial support was received from any organization for the submitted work. Financial relationships: All authors have declared that they have no financial relationships at present or within the previous three years with any organizations that might have an interest in the submitted work. Other relationships: All authors have declared that there are no other relationships or activities that could appear to have influenced the submitted work.

\section{References}

1. Jaillette E, Martin-Loeches I, Artigas A, Nseir S: Optimal care and design of the tracheal cuff in the critically ill patient. Ann Intensive Care. 2014, 4:7. 10.1186/2110-5820-4-7

2. Sakuraba S, Serita R, Kuribayashi J, Kosugi S, Arisaka H, Yoshida K, Takeda J: Comparison of tracheal diameter measured by chest X-ray and by computed tomography. Anesth Res Pract. 2010, 269171. $10.1155 / 2010 / 269171$

3. Muehleman C, Li J, Zhong Z, Brankov JG, Wernick MN: Multiple-image radiography for human soft tissue. J Anat. 2006, 208:115-124. 10.1111/j.1469-7580.2006.00502.x

4. Edeh I, Olowoyeye O, Abonyi L, Awosanya G, Eze C, Omiyi D: Common factors affecting radiographic diagnostic quality in X-ray facilities in Lagos. J Med Imaging Radiat Sci. 2012, 43:108-111. 10.1016/j.jmir.2011.11.001

5. Gaddis ML, Gaddis GM: Introduction to biostatistics: part 4, statistical inference techniques in hypothesis testing. Ann Emerg Med. 1990, 19:820-825. 10.1016/S0196-0644(05)81712-3

6. Patra P: Sample size in clinical research, the number we need . Int J Med Sci Pub Health. 2012, 1:5-9.

7. Sunder Rao PSS, Richard J: An Introduction to Biostatistics: A Manual for Students in Health Sciences, 4th Edition. Prentice Hall of India, New Delhi; 2006.

8. Karmali S, Rose P: Tracheal tube size in adults undergoing elective surgery - a narrative review . Anaesthesia. 2020, 75:1529-1539. 10.1111/anae.15041

9. Touman AA, Stratakos GK: Long-term complications of tracheal intubation. Tracheal Intubation. Erbay RH (ed): IntechOpen, 2018. 10.5772/intechopen.74160

10. Sudhoff TH, Seidl RO, Estel B, Coordes A: Association of oversized tracheal tubes and cuff overinsufflation with postintubation tracheal ruptures. Clin Exp Otorhinolaryngol. 2015, 8:409-415. 10.3342/ceo.2015.8.4.409

11. Finholt DA, Henry DB, Raphaely RC: Factors affecting leak around tracheal tubes in children . Can Anaesth Soc J. 1985, 32:326-329. 10.1007/bf03011335

12. Williamson P, James AL, Phillips MJ, Sampson DD, Hillman DR, Eastwood PR: Quantifying tracheobronchial tree dimensions: methods, limitations and emerging techniques. Eur Respir J. 2009, 34:42-55. 10.1183/09031936.00020408

13. Mihara F, Fukuya T, Nakata H, Mizuno S, Russell WJ, Hosoda Y: Normal age-related alterations on chest radiography. Acta Radiol. 1993, 34:53-58. 10.1177\%2F028418519303400112

14. Breatnach E, Abbott GC, Fraser RG: Dimensions of the normal human trachea. Am J Roentgenol. 1984, 142:903-906. 10.2214/air.142.5.903 